\title{
The Cosmos Project: a Journey to the Stars
}

There seems to be some agreement that 'science for all' does not necessarily mean 'one size fits all' (Lynch, 2001).

Teaching scientific disciplines in schools has been traditionally concerned with delivering science as a product with a main focus on its conceptual structure. In our research we propose to concentrate on science as a process, putting it in the societal context. We introduce the Cosmos project that aims to explore the use of narrative and performative languages, as well as new media technologies in relation to delivering complex scientific topics to pre-school children aged three to six. We created a theatrical piece and developed a set of new interactive preschool activities that enabled young learners to participate and contribute to their learning through physical engagement enhanced by modern technologies. This paper presents a critical discussion about the recent tendencies in teaching science to young learners; the rationale for the Cosmos project and its main research objectives. It will conclude with evaluation of the pre- and postperformance educational activities.

Keywords: performance, science communication, Early Years education, kinaesthetic engagement.

\section{Introduction}

Learning cannot occur without engagement. Learning through play and within imaginative contexts are core principles to Early Years education (Craft 2000, Edwards et. al 1998). Theatre has a long history of using its interactive nature and the concomitant engagement to teach various disciplines to young learners (Jackson 1993, Redington 1983). Previous research has defined the different ways young children engage with performance (Weddell 2003), whilst recent research into children's theatre argues for a dynamic partnership with schools, teachers and students to both 
engage with the curriculum and place the young people as co-researchers (Gattenhof and Radvan 2009). Various drama techniques, as stated in "'I wonder ...': A Creative Science Springboard" resource for science teachers (2006), can significantly enhance teaching and delivery, student motivation and creative learning. Total engagement by the children throughout a theatrical performance (if achieved) could suggest the efficacy of using drama to engage and stimulate the young brain. Theatre offers different modes of engagement and also participation at selected moments that could be successful in sustaining young learners' concentration. Although both semiotic and narrative engagement could play a strong role in enhancing children's comprehension (Aram and Mor, 2009), the kinaesthetic involvement often is the strongest means of participation that supports greatest memory. In our research we look into the fusion of different performative languages, working at semiotic, kinaesthetic, and narrative level, and introduce them into a performance through different media at different times. We also build upon the theory of multiple intelligences proposed by Gardner (1993) that lays out a pluralist view of the mind, stating that "people have different cognitive strengths and contrasting cognitive styles' (Gardner 1993, p. 6). Gardner's theory had a positive impact on educational policy makers due to the strong case it makes for 'the value of artistic subjects as viable roads to learning' (Guss 2005, p. 43), and also for its use by education professionals to advocate for a more childcentred approach to teaching. We acknowledge, however, that his theories have limitations for drama and theatre educationalists. Our study is in agreement with Guss (2005) that although Gardner's theory presents symbolic play as a manifestation of intra- and inter- personal intelligences, it does not look deeper at the complexities involved in symbolic play. Nonetheless, we build upon this theoretical framework to argue that theatre, because of its combination of complex symbolic forms, supports 
strongly young learners in understanding complex conceptual ideas, engaging them on differing levels.

The Cosmos project was conceived to give young learners an opportunity to gain knowledge of Deep Space and the stars and to develop new approaches to pedagogy arguably taking the risks of pushing the curriculum further. The Early Years Foundation Stage does not include the understanding of the workings of the Universe within its curriculum. Normally, at that stage children are grappling with notions of the immediate world around them. At present, a number of researchers argue that using drama and performative methods to teach science focuses more on creativity, rather than scientific understanding (Ødegaard 2003). This study, however, supports Solomon (1999), finding that learners can develop the understanding of science through creative narratives instead of putting the emphasis on memorizing precise scientific definitions. Indeed, stories are quite memorable and, furthermore, easy to comprehend. Newton (2002) and Hughes (1988) point out that because all the elements in a narrative are connected, it can be perceived by the learners as a unit of imagination and, furthermore, encourages child participation in in-class discussions. Nowadays, there is a need to develop innovative projects and resources, in order to facilitate a deeper understanding of scientific topics in a more enjoyable and interactive way. It is also necessary to design learning materials that allow freedom of interpretation (Negrete and Lartigue 2004, Sutton 1992, Nunan and Homer 1981). Osborne (2008, p. 328) articulates further that science education needs a new vision that every advanced society should offer its young people '... it [science education] opens fascinating windows to seeing the world in a totally different way: because it is intellectually challenging; because it transforms our understanding of who and what we are.' 
The Cosmos project attempted to address the aforementioned issues through developing creative approaches to pedagogy. We also aimed to examine the nature of didacticism in the performative context enhanced by modern technologies, which at present act as an inseparable part of the teacher-learner interaction and cooperative information exchange, becoming a necessity in every classroom (... 2008, Marsh 2005). Information and Communication Technologies (ICTs) also generally integrate with constructivism's emphasis on individual learning in a socio-cultural setting (Selwyn et al. 2005), which promotes personalized construction of meaning and the active role of the learner in the interpretation of reality (Larochelle and Bednarz 1998). In our project, we boost the use of Blue Screen technologies to support the individual audience members in learning about, for example, the concept of gravity and bodies in space. The goal here is to enable the children to interact with, and make an impact on, a digitally produced environment.

Aram and Mor 2009 and Elam 2002 define theatre as a weave of drastically distinct means of expression and as a total mode of representation surrounding the spectator in multiple stimuli. In this context, our performance research investigates how the audience might (i) physically interact with scientific concepts, through kinaesthetic activities and multimedia environments, (ii) remember scientific concepts that have been expressed through varied performance languages, and (iii) form opinions about science through emotional experiences/narratives. We examine the potential to break down barriers of audience participation - asking how the viewers can be both spectator and 'spect-actor' (to appropriate Boal's (1979) term), as they interact with both performers and the performance environments - digital and real.

\section{The Study}


Cosmos (Feb 2008 - May 2009) was a two year regional educational programme created by 40 Nottingham Trent University (NTU) Theatre Design undergraduates, 25 professionals (artists, teachers, scientists, technicians), and over 150 children. It was targeted at children and Early Years educators in schools/family centres in Nottingham and Leicester. It consisted of a full length professional theatre production, with integrated audience participation and differentiated creative reflection upon the experience at the end; and education resources and a suite of learning activities designed and manufactured specifically for subsequent use at school.

The audience/learners were engaged physically with the concepts of 'many' (i.e. what lies beyond our planet); 'distance' (i.e. cosmological objects near and far); and 'exploration' (i.e. learning about the world through doing). These science concepts were communicated in performance by (i) participatory and kinaesthetic action; (ii) theatre forms with a high emphasis on visual spectacle; (iii) a fusion of different performance languages; and (iv) narratives promoting empathy with the main protagonist's emotional experiences as she journeys through space. Our goal was to explore whether the pupils' engagement and understanding of scientific concepts was supported by these devices, ultimately aiming to address four research questions: (1) did active participation in the performance maximise children's scientific engagement and understanding? (2) did witnessing spectacle create memorable (recoverable) experiences? (3) did the fusion of performance languages (e.g. the relationship between the abstract dance and linear verbal narrative text; digital space and the crafted world of the object; between music and designed space) engage different learning styles? (4) did emotional engagement and empathy with characters re-enforce the learning of the science concepts? 
There were four levels to the study: research and development (R\&D); Cosmos performance; Cosmos educational resources; and evaluation (pre- and postperformance).

\section{$\mathbf{R} \& \mathbf{D}$}

The Cosmos programme was shaped through two R \& D phases. In Phase One, (Feb March 2008), we worked with 60 children to explore: (1) the nature of scientific enquiry and its relationship to a young child's learning; (2) narratives and emotional content in relation to scientific learning; and (3) the relationship between participation and interdisciplinary forms (such as multimedia) as means to explore complex scientific concepts.

In R\&D Phase Two (Oct - Nov 2008) we (1) researched further into different, interactive narrative; (2) generated high quality visual content for the theatrical piece (e.g. set design, video, projections, etc); and (3) developed educational resources, working closely with teachers, scientific collaborators and family centres. These activities were underpinned by investigating age-appropriate learning styles, particularly designing and testing a number of kinaesthetic/multimedia activities.

\section{Cosmos Performance}

The Cosmos performance took place at Waverley Studio Theatre, NTU, 6-13 March, 2009 and at Curve Leicester, 27-30 May, 2009. The audience followed the main protagonist (The Child) on a physical and emotional journey through the Cosmos in search of her lost Story Star. After hearing stories of the origins of the universe, they followed her up a ladder beyond the Earth's atmosphere, met anthropomorphic planet 'characters' and journeyed to the far edges of the universe on their quest . Emotionally, the narrative explores loss, grief, independence and renewal (Fig. 1).

Figure 1: Little Girl climbing a ladder into space. 


\section{Participation and Kinaesthetic Learning}

Children engaged with the performance through physical participation modelled by the performers. They explored the relationship of the individual to the vastness of space through the notion of a single grain in a sea of sand particles; the motion of planetary bodies in space and concept of gravity through dance (e.g. being physically lifted by dancers and orbited through space); and the 'life and death of a star' in group activity through movement with objects (Fig. 2). All these activities took place in the context of digital projections, lighting effects and shifting musical modalities.

Figure 2: Young learners engaging with the performance of Cosmos.

\section{Visual Spectacle}

The 'awe and wonder' necessary for young learners to feel engaged, were engendered through the use of spectacle. This involved puppetry, costumes, film and the use of space and lighting. The audience moved through the spectacle on a physical journey from one cosmic space to another. Digital media working alongside physical objects enabled multi-sensory layers of understanding and learning to take place during the performance. As an example, to explore gravity and our relationship to space beyond Earth's orbit - and to create the effect of 'floating in space' - Blue Screen technology was utilised. During the final part of the performance, young learners volunteered to be placed on a piece of blue lycra held and rotated by the actors. The image of a child was captured digitally and projected onto the screen above them. The effect was that the child could both feel and identify themselves flying in space (Fig. 3).

Figure 3: A young learner engaging with the blue screen technology.

\section{Fusion of Different Performance Languages}

Integral to the performance was the layering of visual and aural forms - the Child character's journey told through the interaction of dance, rhythmic poetic storytelling, 
film, puppetry, and music. The different performance forms allowed the telling of both the emotional and scientific narratives in multilayered ways, engaging children across their individual learning styles. For example, within the 'liminal' world of Earth's orbit, young learners were playing in sand, surrounded by projected film of a child leaving her father, whilst witnessing a live dance about defying gravity.

\section{Narratives Promoting Empathy}

The main protagonist's quest - leaving home, gaining independence and integrating into the wider world - reflected the life experiences of the audience at their age. The performance encouraged participants to identify with the Child's problems and emotions, developing their growing skills in empathy. In her journey the Child meets the Solar Planets, and engages with them as anthropomorphic (dance) characters (Fig. 5). These different encounters reflect the young learners' varied experiences of integration or isolation within their school community. Puppets were safe and empathetic characters, guided the audience through the action.

Figure 5: Meeting Attractive Saturn / the Isolated Plutoids.

\section{Cosmos Educational Resources}

A suite of educational and associated kinaesthetic activities was developed and presented to participating schools. These resources contained a follow up to the production (for those who saw it), and a stand alone educational package. Following similar principles to the Cosmos production itself, the resources include teaching materials and strategies using dance, visual art, play and circle time to explore the elements of cosmic space. The package was structured to be delivered intensively (five consecutive days), or on a weekly basis throughout a half-term science block. Each scientific concept was to be explored through verbal, kinaesthetic and visual 
activities, applying principles and practice from the Early Years curriculum as delivered in Foundation and Key Stage 1.

Cosmos - The Book is the central artefact in the Resource package. Its purpose is to engage the pupils in the human story of Cosmos to maintain their focus on the scientific learning. The book is read out by the teacher, but invites interactive responses. The story connects with children's physical activities at other times during the day's work on science. This scientific learning then stimulates contemplation and discussion of the pupil's emotional life experiences, enabling the learner to associate with and memorise the original scientific principles. The book has five chapters narrating the Child's journey, each of which covers the following learning areas: scientific knowledge, emotional literacy, and verbal literacy:

- Chapter One posits the scale of the visible (night-time) universe and alludes to notions of life cycles, emotional and spatial voids, and the relationship of the Earth to bodies in space beyond.

- Chapter Two develops further the idea of human and cosmic scale, through the analogy of a grain of sand. Gravity is explored through poetic metaphors - and connected to the emotional journey of parental separation and loss pertinent to children at this age.

- Chapter Three is devoted to the concept of the Solar Planetary System. Its relative scale and orbital motion are explored through dance activities, and by the kinaesthetic use of common objects (fruits) easily identifiable and memorable to the learner. The actual physical properties of planets are suggested through play activities with liquids, solids and colour.

- Chapter Four introduces constellations, life cycles of stars and distance/light/emptiness. These important concepts are re-enforced by a 
narrative emphasis on the need to tell stories (a small child's primary method of communicating her/his understanding of the world). The idea of constellations is reinforced by connective drawing. The concept of stellar life cycles and recycled matter is illustrated through activities with bursting balloons. The making of 'listening devices' builds children's confidence to tell their stories, and introduces sound as an important astronomical principle.

- Chapter Five emphasises notions of memory and loss as the protagonist returns through the solar system to her parental home. Archetypally, she has changed and grown through her quest. The solar system's structure is reprised by creating installations and movement work. The planets' physical properties are re-visited through their anthropomorphic/emotional qualities. Art exercises are used to invite the child to examine their own place in the 'social universe'. Circle time is used as a plenary device to consider the scientific and emotional learning of the project.

These resources were developed to address a gap in the curriculum by examining ideas that are normally dealt with by older pupils through conventional teaching methods. The work undertaken demonstrates that these sophisticated concepts and scientific facts can be explored meaningfully in Early Years, through the different strategies employed.

\section{Evaluation}

In order to discover the impact of the Cosmos project on young learners, we employed the following methodology for data collection and evaluation: (1) mapping exercise with the children; (2) audio-visual methods and creative activities (e.g. drawings by children, listening to the 'listening devices', and responding with their 
own stories); (3) questionnaires with teachers; and finally, (4) ongoing dialogic reflection with teachers, scientists, artists and undergraduate students. The evaluation procedure consisted of pre-performance and post-performance stages.

\section{Pre-Performance Evaluation}

For the pre-performance evaluation the young learners were assigned a creative exploratory task named the Map of Universal Experience, through which we attempted to explore the children's conceptual understanding of Earth and Space before seeing the actual performance. The map (Fig. 6) was designed to find out how much the children knew about the world beyond them, what the universe is made up of, and to investigate their understanding of the concept of distance.

Figure 6: The Map of Universal Experience (Berridge School and Glenbrook School, Nottingham).

This interactive map consisted of progressively larger circles that represented what young learners know about their position in space (i.e. home, school, city, country, planet). Children were given a number of images and symbols, which were designed specifically for this activity to give them some visual clues on the subject. In addition, some of their responses were written down on the pieces of paper and then placed on the map firstly by a teacher, and after that by children themselves.

Our findings suggest that the level of understanding of what is beyond our planet differs from school to school. Some children had more exposure than others to media, such as computer games and television, enhancing their knowledge of the solar system and facilitating discussions about the possibility of life on other planets (i.e. aliens). There were, however, consistent patterns of young learners having difficulty in comprehending the concept of distance between planets and stars, and in understanding the notion of orbiting (the predominant opinion was that the Moon takes the place of the Sun during the night-time). It was also observed that children 
often strove to give correct answers in order to please their teachers. Nevertheless, as a creative evaluation tool to assess children's existing understanding (and for comparative analysis) the mapping exercise was successful. It also served as a teaching tool for scientific debate and enquiry in that it engaged young learners in discussions about the scale, colour and positioning of the planets and in stimulating their ability to question the world around them. Some of the questions that emerged during discussions included: Does space have earthquakes? Why do the clouds go orange/pink when the sun is sinking? Is a 'spaceologist' someone who explores space?

\section{Post-Performance Evaluation}

Six groups of children (each consisted of six participants) from three schools were involved in the post-performance evaluation activities, which once more involved the Map of Universal Experience. These exercises focused on the progress young learners made in developing their knowledge about the space and the Universe. In their recapping of the spectacle, the children mostly remembered the story of the Little Girl and her journey to find the Story Star. They especially remembered her meeting angry Mars and the little planets at the edge of the universe, as well as the Little Girl tying their shoe laces. They remembered her crying when she found the Story Star and asked her to tell her a story: 'She was crying and the little girl said, tell me a story and then she was there.' Teachers described the young learners' recall on the emotional content of the performance as impressive and were surprised with the level of detail they were able to remember. Figure 7 is based on teachers' evaluation and illustrates the children's understanding of the scientific concepts presented to them throughout the project.

Figure 7: Young learners' understanding of the scientific concepts. 
Across the schools, there was a good understanding of the concept of many. Most children could remember Jupiter and Mars, recalling them as red/orange and large, and red and small respectively. Some young learners remembered Saturn, especially its rings around it, and Mercury as a small planet, and Mace Mace and Eris as being small planets furthest away. Some children gained an understanding that the planets orbited, describing them as 'going around and around'.

The understanding gained around the concept of distance was the least successful of all the concepts. Many understood that space is far away (beyond the clouds) mainly through the use of scenery, and some children described Jupiter and Saturn as being in deepest space. Most pupils understood that the sun and moon were beyond the clouds, placing them on the map further out in space. There was some continued difficulty in comprehending that stars are further away than the planets, although during the post evaluation there was healthy debate and discrepancy amongst the children around this notion. The children in one school who had used the education resources and followed the work up in the classroom over a period of time, were able to describe that is was hotter the closer you got to the sun, whilst it was colder the further away you were.

The teachers who were involved in the post evaluation mapping exercise expressed the opinion that the concept of scientific exploration had been gained by the children mainly through their empathy with the young child on her journey through space. All participating teachers agreed that there was full engagement with the performance and the story, achieved mainly through the use of multiple stimuli and participation to engage different learning styles. Although this engagement enabled partial understanding of the science concepts it was an excellent stimulus and introduction into them. 


\section{Data Analysis}

We analyzed the collected data from three important research perspectives:

(1) Academic perspective:

Cosmos Research Seminar was held on the $11^{\text {th }}$ of March 2009 at Nottingham Trent University. A number of researchers, teachers, artists, scientists and undergraduate students gathered together to discuss the outcomes of the Cosmos educational programme and performance, the importance of the project, and its potential for developing various pre-school learning activities. Researchers and academics were concerned with the current teaching strategies in secondary and higher education learning, with a heavy emphasis on auditory teaching modes and within the confines of an over restictive curriculum. They argued that this should be avoided in pre-school and primary education. Children are already 'scientists'. They are curious by nature, they explore and enquire. This notion of enquiry is about experiencing a process - not learning statements and facts. Therefore it was important that children could choose when and how to engage with the performance of Cosmos, a choice which is often taken away in school. Another interesting perception was the curious tendency amongst University science teachers to work in schools to explore and research with very young learners. It was argued that in later years, science can become 'dry' and lose its 'magic'. Thus it is vital for young children to discover and learn about science through a multi-textural and multi-sensory experience that included a variety of media. In addition, an astronomer remarked that it was a common conception that astronomy is quite detached from society; whereby, stars are used to create stories to interpret reality (e.g. zodiac, astrology).

(2) Teachers' Perspective: 
All participating teachers (eight in total) were asked to keep a diary of observations throughout the duration of the project and fill in a questionnaire. The main consensus amongst them was that the children enjoyed physically interacting with the props and actors, as well as their enjoyment at being immersed in the 'Cosmos' through the use of lighting, video and projections. It was also noted by all teachers that different types of participation employed throughout the performance enabled memories of it to be long lasting. They noted that the pupils kept talking about the performance weeks after they saw it. The involvement of the children in a piece of interactive theatre, as opposed to them being merely spectators, was beneficial in maintaining the young learners' concentration throughout an one hour long performance. Figure 8 illustrates the ratio between the different types of learning observed by the teachers during the performance, and the most memorable moments the young learners recalled in the weeks after the performance

Figure 8: The ratio between different types of learning used throughout the Cosmos project.

The data evaluation exemplified that although both semiotic and narrative engagement of young learners enhanced their comprehension of scientific concepts, the kinaesthetic involvement supported greatest memory

Some teachers emphasized that such concepts as 'many' and 'distance' are massive things for very young children to comprehend. However, the fact that they gained knowledge about the Cosmos, mainly through the sensory experience of the performance and educational activities, was absolutely crucial. Additionally, most children recognized (with the help of multimedia) that the Little Girl had left her Father and had journeyed to the stars to look for her Story Star, grasping the scientific concept of exploration. It was a key finding, albeit a predictable one, that the educational resources proved very useful in deepening the children's understanding of 
the three concepts as further investigation could take place back in the classroom through a creative approach.

\section{Children's Perspective}

As mentioned above, the interactive evaluative exercise took place pre- and postperformance with young learners from across 3 schools, whilst the conversations were conducted with all the children immediately at the end of the piece. Children were asked to listen to the 'listening devices' and respond with their stories, or draw their most memorable experiences. Some of the young learners, for example, drew themselves floating in 'cosmos', whilst using the Blue Screen technology (Fig. 9). Others drew themselves climbing up the ladder and sliding down into the sand, dancing with the spheres, and being carried by the actors through space. Some of the children concentrated on drawing the Little Girl, the Story Star, the Sky Monkey puppet, the orbiting planets (especially Mars), and the child leaving and then being reunited with her father. Some of their comments included: 'We played with balls, they were planets', 'Saturn has rings, she had a skirt that looked like rings and she had a ribbon.'

Figure 9: Children's drawings of their experience of 'floating in space'.

Unsurprisingly, both the stories and the drawings are full of cosmological phenomena, but what was unexpected for the teachers is the fact that children who didn't usually participate in storytelling were eager to contribute. One little girl who had recently joined a school and as yet had not spoken, began to talk about the things she was seeing in front of her. Interestingly, many of the most memorable images recalled, were those developed through the initial research and development phases, or those moments within which the young people were actively engaged. 


\section{Research Outcomes and Limitations}

The results from the immediate dialogue with children (i.e. audio-visual and creative activities) affirmed one of the main findings of this research that their most memorable moments were connected to various kinaesthetic activities young learners were involved in during the performance and evaluation stages. Furthermore, our research outcomes suggest that the emotional content of the piece carried greater weight than the scientific content, suggesting that it might have been the power of performance to create empathy for others that enabled a memorable experience to happen, and through this, captured a scientific imagination. Through the process of evaluation, despite working closely with teachers to formulate the methodologies, it was still problematic to assess outcomes with young learners when relying on their memory and also verbal and written responses. The drawing feedback at the end of the performance enabled the children to respond most immediately without recourse to spoken language. However an understanding of the impact still needed to be mediated orally. The mapping exercise was a useful data collection tool (although still relying heavily upon oral remembered responses), which was playful and interactive. In itself the map was conceived as an evaluation and reflection tool but it also had excellent potential as a teaching and learning device. The nuance between evaluating and teaching was at times tricky whilst using the map, as there was a temptation to 'teach' when discovering what the children didn't know .However remaining open to all the children's observations was important to capturing the evaluation.

An understanding of other planets in our solar system, of Cosmic distance, and the notion of exploration was understood at varying degrees of success. Most staff felt that all of the scientific concepts had been introduced to young learners but they did not manage to gain a complete understanding of them. However, they were 
unconcerned by the partial understanding of some of the concepts. The teachers and the scientists involved in this project both argued that it was the conceptual learning that was more important than the learning of hard facts such as the names and order of the planets. This raised an interesting pedagogical question of whether a theatrical performance should support the factual learning or contribute more to the conceptual learning? The performance was not intended as a 'drop in, drop out' (Gattenhof and Radvan 2009) moment, but as integral to scientific learning that would continue within the course of the term. As would be expected, there was a greater understanding of the scientific concepts by children from those schools, where teachers extended the learning into the curriculum and back in the classroom. Interestingly, the two schools who were closely involved in our research have decided to use Space as a curriculum topic in the future, and apply kinaesthetic reflective evaluations (such as dance, drama) as a useful model for evaluation of Early Years learning,

Although this specific action research has been addressing the efficacy of using performance within the communication of scientific ideas and concepts, we have engaged in a model of practice that involves a close working partnership with Early Years educators and young learners. In attempting to address their needs and questions, we have trusted that the work is meaningful to all participants on both an emotional and intellectual level. We believe that every pupil has a right to be involved in and experience high quality learning through creative and cultural opportunities. The question we would ask educators is whether cultural entitlement implies that young learners are passive recipients of cultural artefacts or whether there should be an opportunity for young people to be co- creators in their cultural entitlement.

\section{Conclusion}


The Cosmos project proved to be a valuable, in many cases, first introduction to space and the planets for young children. One might ask however, whether it is necessary to teach such complex scientific topics to very young learners. Our research indicates that children were capable of grasping complex scientific concepts through the programme we have delivered. Feedback from teachers and children indicates that performance encourages children's curiosity in the world around them and engages them in greater scientific understanding. Our evidence shows that children achieved either 'secure' or 'partial' understanding of all the scientific concepts in 'Cosmos'. Our pre-performance evaluation indicated that children had very little understanding of any planets and that they had thought that the sun and the moon are sitting in the cloud'. Post-performance evaluation proved, however, that in schools where young learners hadn't yet worked with the educational resource pack, their connection with or remembrance of the piece was strongest on an emotional level. On the other hand, in those schools where the staff had followed up the 'Cosmos' work scientifically, children remembered planets and had a sense that stars, suns and moons were 'beyond the clouds' - i.e. in space.

One of the main findings of our research is that performance which employs complex multiple forms, can have an impact on scientific understanding because of its multi-sensory and multi-textual fabrication. Its value lies in the power to engage all the senses and learning styles as well as the 'intellect'. The active and kinaesthetic type of learning explored by Cosmos has implications for how performance could be valued and embedded in teaching and learning across all areas of the curriculum, not as a one off but as part of a whole programme's work. As a model of partnership working it contributes to the discussion of the nature of 'cultural entitlement'. 
Following on from our findings, we are interested in investigating the link between emotion, memory recall and scientific understanding.

\section{Acknowledgements}

The Cosmos project is funded by Arts Council England, East Midlands Development Agency (EMDA) through the Ignite! Science Programme, Leicester Theatre Trust and Centre for Effective Learning in Science (CELS) at NTU. This is a partnership project between Dragon Breath Theatre, Narrative and Interactive Arts, NTU and CELS, NTU Alumni Fund, Leicester Theatre Trust and Dance 4 National Dance Agency in the East Midlands.

\section{References}

1. Aram, D. and Mor, S. 2009. Theatre for a Young Audience: How Can We Better Prepare Kindergartners for the Experience?, Research in Drama Education: The Journal of Applied Theatre and Performance, 14 (3): 391-409.

2. Boal, A. 1979. Theatre of the Oppressed. (McBride, C. A. and McBride, M.O. L. Trans.), New York: Urizen, (original work published 1974).

3. Craft, A. 2000. Creativity across the Primary Curriculum: Framing and Developing Practice, London: Routledge.

4. Edwards, C., Gandini, L., Forman, G. eds. 1998. The Hundred Languages of Children: The Reggio Emilia Approach--Advanced Reflections. JAI Press: London.

5. Elam, K. ed. 2002. The Semiotics of Theatre and Drama, $2^{\text {nd }}$ New York: Routledge.

6. Gardner, H. 1983. Frames of Mind: the Theory of Multiple Intelligences. New York: Basic Books.

7. Gardner, H. 1993. Multiple Intelligences: The Theory and Practice, New York: HarperCollins. 
8. Gattenhof, S. and Radvan, M. 2009. In the Mouth of the Imagination: Positioning Children as Co-researchers and Co-artists to Create a Professional Children's Theatre Production, Research in Drama Education: The Journal of Applied Theatre and Performance, 14 (2): 211-224.

9. Guss, F. G. 2005. Dramatic Playing Beyond the Theory of Multiple Intelligences, Research in Drama Education, 10 (1): 43-54.

10. Hughes, T. 1988. Myth and Education in Imagination and Education in Imagination and Education, eds. Egan, K. and Nadaner, D., Open University Press, $30-44$.

$11 . .$.

12. Larochelle, M. and Bednarz N. (1998) Constructivism and Education Beyond Epistemological Correctness in Constructivism and Education, eds. Larochelle, M., Bednarz, N., and Garrison, J., Cambridge: Cambridge University Press, 3-20.

13. Marsh, J. ed. 2005. Popular Culture, New Media and Digital Literacy in Early Childhood, London: Routledge.

14. Negrete, A and Lartigue, C. 2004. Learning from Education to Communicate Science as a Good Story, Endeavour, 28 (3).

15. Newton, D.P. 2002. Talking Sense in Science, Routledge: Farmer.

16. Nunan, E.E. and Homer, D. 1981. Science, Science Fiction, and Radical Science Education, Science-Fiction Studies, 8: 311-330.

17. Ødegaard, M. 2003. Dramatic Science. A Critical Review of Drama in Science Education, Studies in Science Education, 39 (1): 75-101.

18. Selwyn, N., Gorard, S. and Furlong, G. J. 2005. Adult Learning in the Digital Age: Information Technology and the Learning Society, London: Routledge. 
19. Solomon, J. 1999. Meta-Scientific Criticisms, Curriculum Innovation and the Propagation of Scientific Culture, Journal of Curriculum Studies, 31: 1-15.

20. Sutton, C. 1992. Words, Science, and Learning, Buckingham: Open University Press.

21. Weddell, C. 2003. The Child Audience, in Children, Meaning - Making and the Arts, ed. Wright, S., Pearson: French Forest, Australia, pp. 135-59. 


\section{Figures}

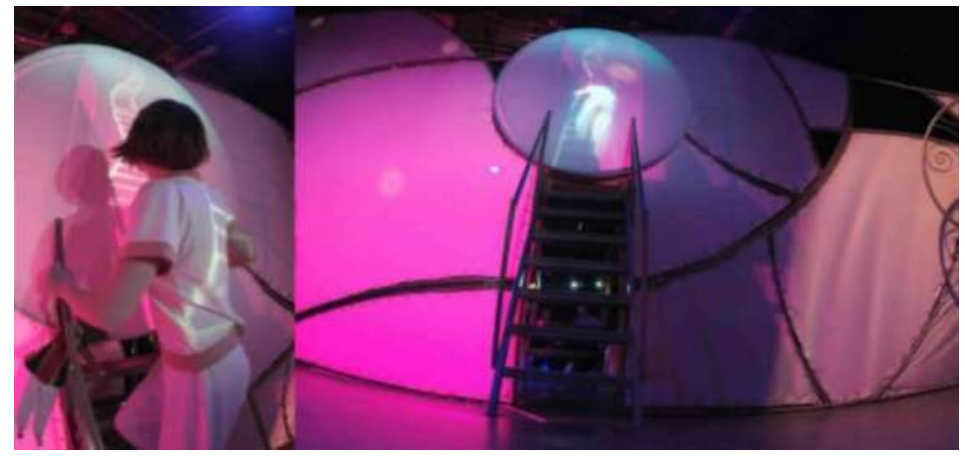

Figure 1: Little Girl climbing a ladder into space.

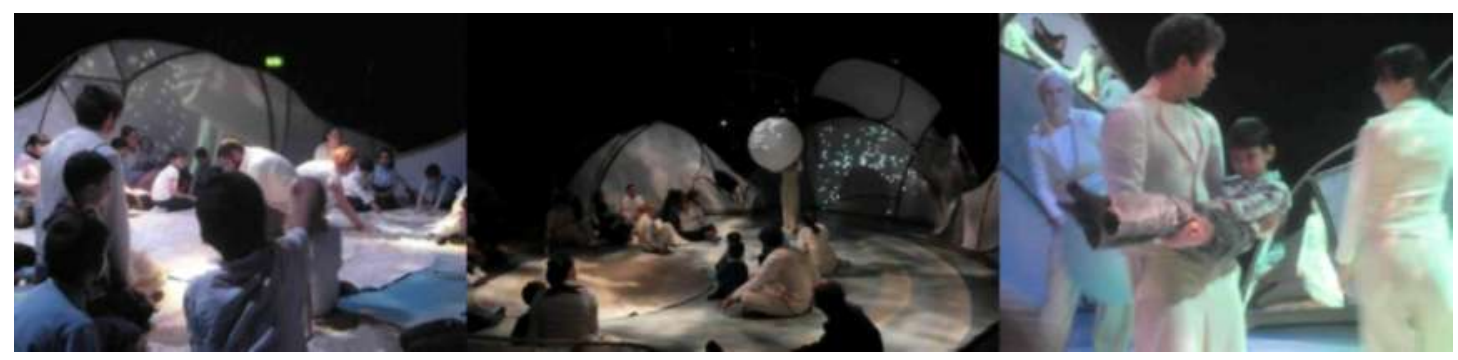

Figure 2: Young learners engaging with the performance of Cosmos.

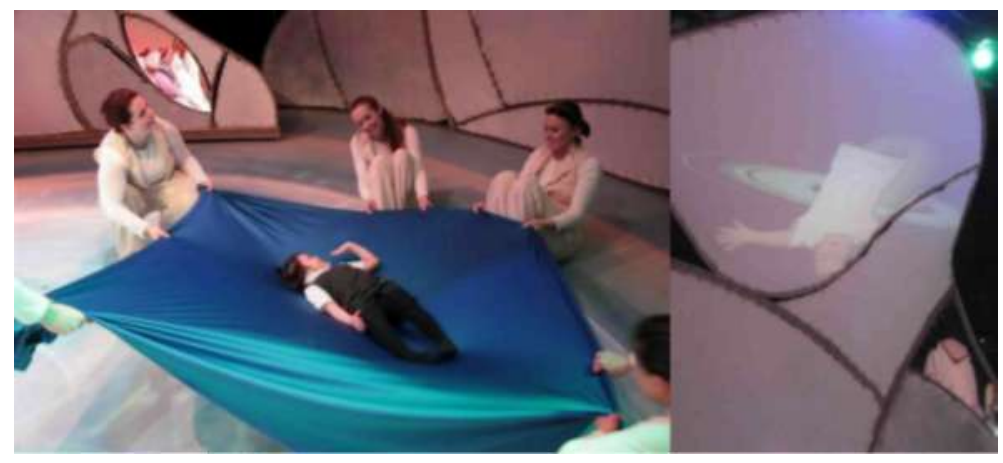

Figure 3: A young learner engaging with the blue screen technology.
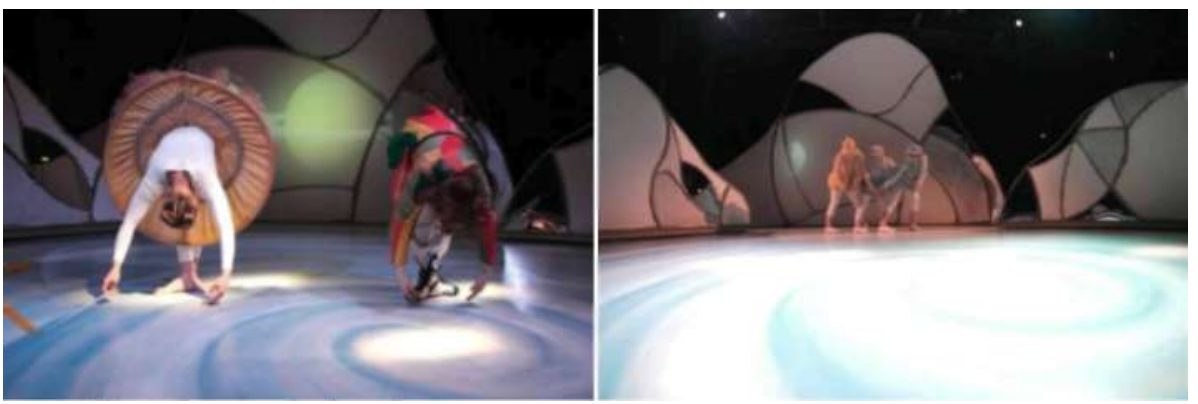
Figure 5: Meeting Attractive Saturn / the Isolated Plutoids.

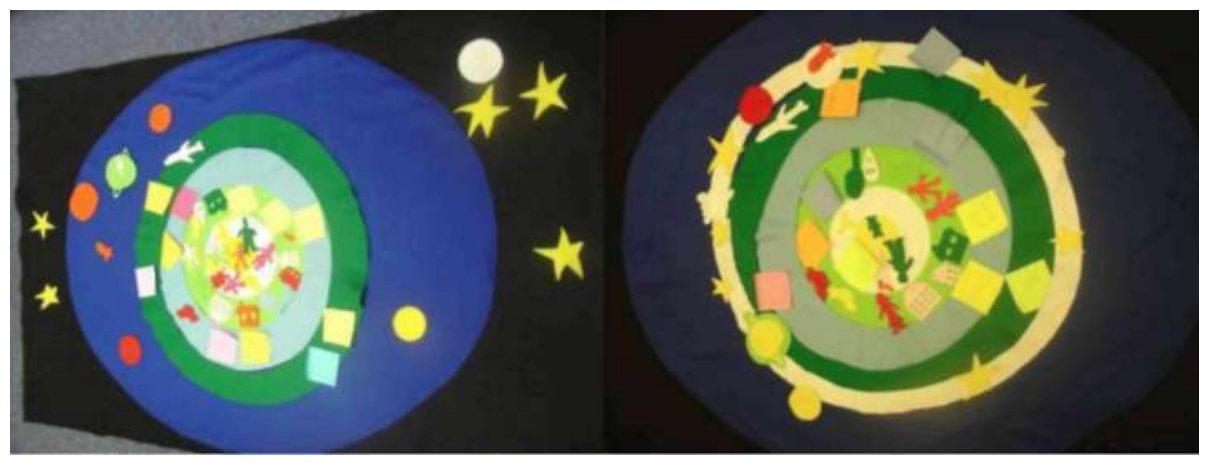

Figure 6: The Map of Universal Experience (Berridge School and Glenbrook School, Nottingham).

\section{Chart Title}

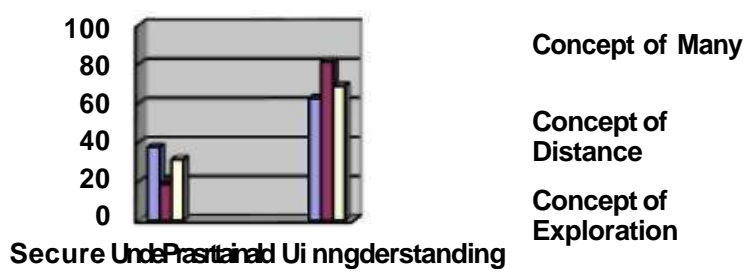

Figure 7: Young learners' understanding of the scientific concepts.

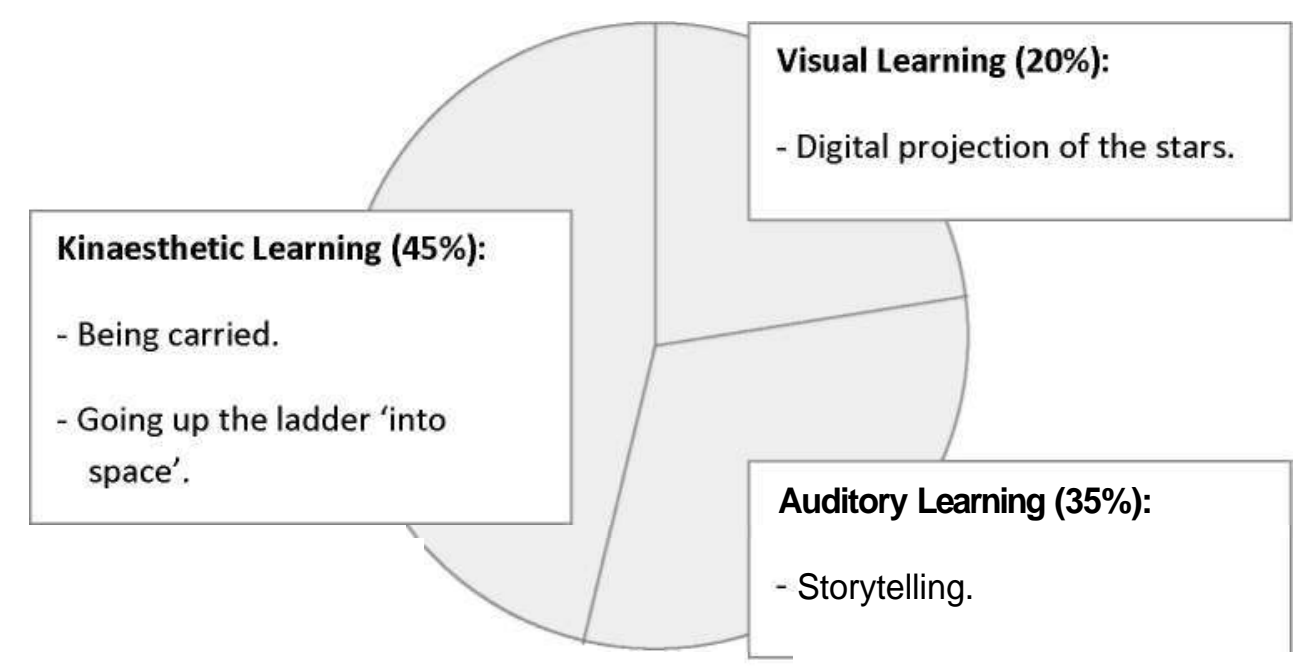

Figure 8: The ratio between different types of learning used thr-o ifghythm th. e Cosmos project. 


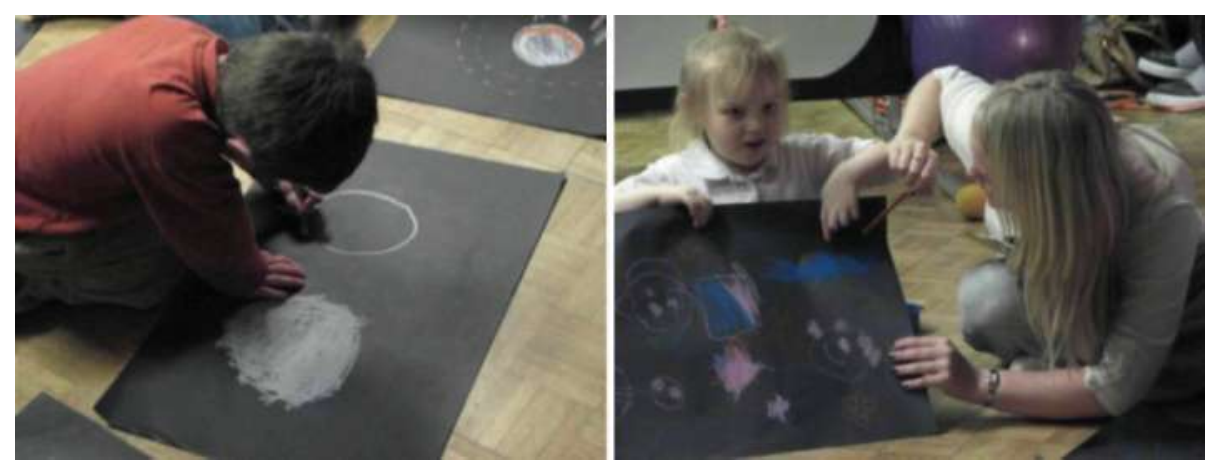

Figure 9: Children's drawings of their experience of 'floating in space'. 